\title{
Can Galantamine Act as an Antidote for Organophosphate Poisoning? A Review
}

\author{
T. H. INDU, D. RAJA, B. MANJUNATHA ${ }^{1}$ AND S. PONNUSANKAR* \\ Department of Pharmacy Practice, JSS College of Pharmacy, Ooty-643 001, ${ }^{1}$ Department of Forensic Medicine and
} Toxicology, JSS Medical College, Mysore-570 015, India

Indu, et al.: Galantamine in the Management of Organophosphate Poisoning

\begin{abstract}
Organophosphate compounds are commonly used as insecticides in rural areas and powerful warfare agents by military personnel. These agents inhibit cholinesterases especially acetylcholinesterase and accumulate acetylcholine causing muscarinic, nicotinic and central nervous system manifestations. Currently, drugs such as atropine, oximes and benzodiazepine are used to treat these symptoms. But these drugs are associated with certain drawbacks and have found to be ineffective in preventing the delayed symptoms. This review analyses the rationalities in considering galantamine as an effective choice in the management of organophosphate toxicity. The mechanism is based on reversible competitive inhibiting property of galantamine on acetylcholinesterase without affecting butylcholinesterase. The drug can prevent the delayed cognitive effects and neurodegeneration by acting as a nicotinic allosteric potentiating ligand. It can cross the blood brain barrier and reversibly inhibit acetylcholinesterase in the brain and decrease the incidence of central nervous system manifestations such as convulsions. The drug is associated with good pharmacokinetic profile, minimal side effects and has been found to be effective as a pretreatment and post treatment agent. Thus, galantamine can be considered as an effective therapeutic agent in management of organophosphate toxicity.
\end{abstract}

Key words: Acetylcholinesterase, galantamine, organophosphate compound, poisoning management, therapeutic approaches

Organophosphate compounds are used as insecticides and powerful warfare agents worldwide. The differences in the properties are based on the substituents attached to the basic moiety. The highly toxic compounds were developed as warfare agents and lesser toxic agents as insecticidal agents ${ }^{[1,2]}$. Among the commonly used agrochemicals, organophosphates were found to be the most preferred one due to their wide spectrum bioactivity and easy availability ${ }^{[3]}$. Parathion, fenthion, malathion, diazinon, chlorpyrifos (Dursban), terbufos, acephate, phorate, methyl parathion, phosmet, azinphos-methyl and dimethoate are the commonly used insecticidal agents. World Health Organization (WHO) has described that these agents belong to the extremely hazardous category, yet no law or policies exist to restrict their availability to the public ${ }^{[4-6]}$. Organophosphate compounds are responsible for large scale accidental poisoning and suicidal poisoning in developed countries ${ }^{[7]}$. Compounds such as soman (1,2,2-trimethyl propylmethyl phosphono fluoridate), sarin (isopropyl methyl phosphono fluoridate), tabun (ethyl dimethyl phosphoramidocyanidate) and VX (ethyl-S- diisopropylamino ethyl methyl phosphono thioate) are used as warfare agents, capable of causing mass destruction in war $^{[8]}$. Thus, organophosphate poisoning became a major public health hazard to be therapeutically managed effectively.

\section{MECHANISM OF ACTION AND CLINICAL SYMPTOMS}

Organophosphate compounds may enter into the human body by ingestion, inhalation or skin absorption and irreversibly inhibit acetylcholinesterase (AChE) in cholinergic synapses. AChE is mainly responsible for the

This is an open access article distributed under terms of the Creative Commons Attribution-NonCommercial-ShareAlike 3.0 License, which allows other the remix, tweak, and build up to the non-commercially, as long as the author is credited and the new creations are licensed under the identical terms.

Accepted 15 June 2016

Revised 08 June 2016

Received 15 May 2015

Indian J Pharm Sci 2016;78(4):428-435 
degradation of acetylcholine (ACh). Organophosphate compounds causes accumulation of ACh in the synaptic cleft $^{[9-11]}$. This overflow of ACh stimulates the nicotinic, muscarinic and central nervous system receptors; leading to elicit clinical complications in patients. Fig. 1 shows the schematic representation of the mechanism of action of organophosphate compounds. Muscarinic stimulation causes acute cholinergic syndrome and the characteristic features are increased rate of secretions from secretory glands such as salivary, bronchial, pancreatic, lacrimal, sweat glands, miosis, blurred vision, bradycardia, vomiting, abdominal cramps, cyanosis, pulmonary edema, wheezing and dyspnea. The increased level of ACh desensitizes the nicotinic receptors and produces symptoms such as muscular twitching, neuromuscular paralysis whereas anxiety, tremor, giddiness and coma are considered as its central nervous system manifestations ${ }^{[11-13]}$.

Intermediate syndrome (type II respiratory failure) is commonly observed in organophosphate poisoned patients and muscle weakness on limb, neck, throat, muscle paralysis and respiratory failure are the associated complications. Generally, intermediate syndrome is observed within 24 to $96 \mathrm{~h}$ after the consumption of organophosphate compound. The delayed effects are often observed in the following 2 to 3 weeks after poisoning. The neurodegeneration observed commonly in organophosphate toxicity in hippocampus, pyriform cortex and amygdala may cause these delayed cognitive effects. The increased level of ACh in the synaptic cleft for a long duration may also be considered as the reason for this syndrome ${ }^{[14,15]}$.

\section{LABORATORY INVESTIGATIONS}

Insecticidal organophosphate poisoning is generally confirmed by the physicians based on the container brought by the patient or the patient's caretaker. The typical clinical manifestations of these compounds including garlic breath may help to diagnose the toxicity. The Peradeniya Organophosphorus Poisoning (POP) scale provides an indication towards the toxicity grade. This scale is based on five major cardinal symptoms of organophosphate poisoning such as heart rate, pinpoint pupil, consciousness, excessive sweating and rate of respiration ${ }^{[16,17]}$. Poisoning Severity Score (PSS) can also be used to monitor the severity based on clinical manifestations ${ }^{[18,19]}$.

The measurement of the extent of inhibition of cholinesterase enzymes indicates the severity of poisoning. The normal values of cholinesterase enzymes in healthy people depend on race, region, malnutrition, liver and renal diseases. The presence of alcohol, nicotine and caffeine can also induce alterations in the levels of cholinesterase. So, the establishment of a baseline value for cholinesterase enzymes in a particular region is very essential ${ }^{[20,21]}$. The quantitative estimation of the cholinesterase from the blood samples can be analyzed using colorimetry ${ }^{[22]}$. These markers can be used for diagnosis and monitoring of the treatment prognosis. The renal and hepatic markers also indicate the severity of organ toxicity. The management, based on these severity grades, may enable the physicians to provide an optimized treatment pattern to each patient. These practices provide a better quality of life to the patient and cause a reduction in the healthcare expenditure burden.

\section{CURRENT TREATMENT OPTIONS}

The management of organophosphate poisoning begins with the removal of toxic contents from the stomach through gastric lavage and nasogastric aspiration. This is followed by providing supportive

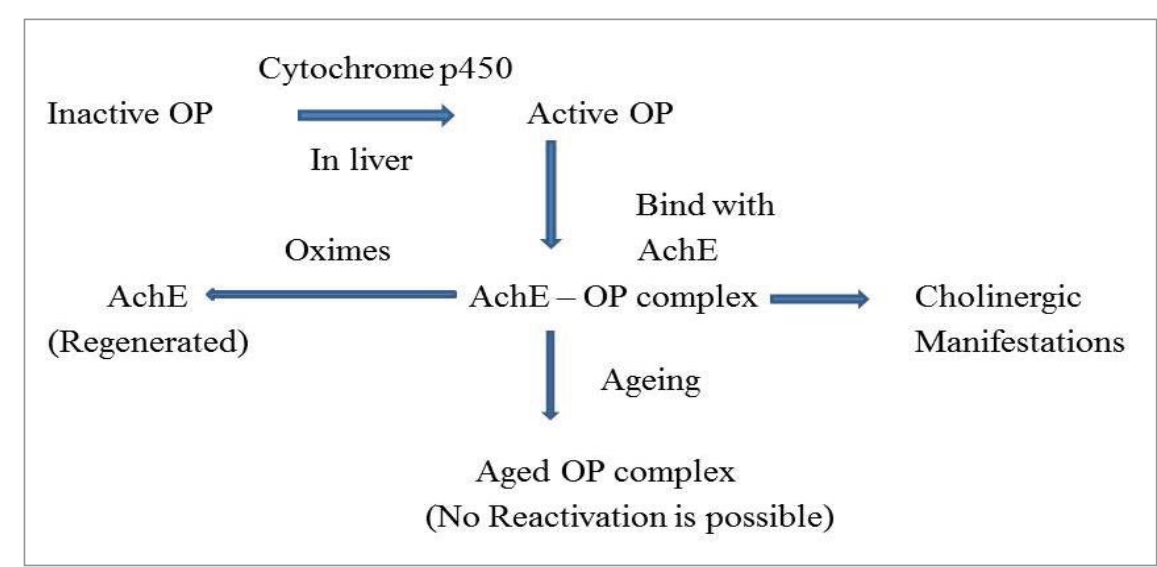

Fig.1: Schematic representation of mechanism of organophosphates.

OP: organophosphate; AchE: acetylcholinestarase 
measures such as oxygen administration and induction of respiratory pressure to the patient. Atropine can be given for symptomatic relief and cholinesterase reactivators (oximes) as an antidote in usual practice. The neurological symptoms such as agitation, delirium, and muscular fasciculation can be treated using benzodiazepines. Atropine inhibits the effects of muscarinic receptors due to the excess ACh. The classical symptoms of organophosphorous poisoning such as salivation, lacrimation, urination, diaphoresis, gastrointestinal motility and emesis can be prevented by the use of atropine. Atropine is always used along with oximes (pralidoxime chloride). Oximes show their effectiveness by reactivating the phosphorylated cholinesterase enzyme after binding with organophosphate compounds. These agents stimulate the nicotinic receptors and reduce the nicotinic symptoms such as muscle fasciculation, hypertension, tachycardia and muscle weakness ${ }^{[23-25]}$.

There are some limitations associated with this treatment strategy. The major problem associated with oximes is ageing process. Ageing can be explained as the process in which, the response to reactivating agents declines with time and the process depends on the type of organophosphate compound. If larger substituents are attached with organophosphate compound, the reactivation rate may be extremely slow. Thus, administration of oximes is time dependent and the treatment should be started as early as possible. Generally this time period is 48 to $72 \mathrm{~h}$. Oximes may not reactivate the muscarinic symptoms of organophosphate poisoning ${ }^{[25,26]}$. Similarly atropine does not have any effects on nicotinic receptors. The improper usage of atropine can cause iatrogenic atropine toxicity and in some cases the drug induces hypersensitivity reactions also ${ }^{[27,28]}$.

There are certain alternative treatment plans to overcome these limitations. Pyridostigmine bromide (PB), a quaternary carbamate compound was approved to manage organophosphate toxicity. People who are under the risk of organophosphate exposure were recommended to administer this compound as a prophylactic agent. The compound reversibly inhibits $\mathrm{AChE}$ and butylcholinesterase (BChE) without crossing blood brain barrier. Therefore, organophosphate compounds bind with $\mathrm{AChE}$ in a less extent. Immediately after the exposure of organophosphates, patient should be given with atropine and oximes. PB can increase the survival rates in the victims exposed to nerve agent toxicity; still, the drug is not encouraged widely due to its long term side effects and high dose to be administered. BChE can act as an endogenous scavenger for organophosphate compound, which is blocked by pyridostigmine. The inability of the compound to prevent central nervous system manifestations such as seizures may demand the inclusion of anticonvulsants into the treatment pattern $^{[29,30]}$.

The reversible AChE inhibitors such as physostigmine, tacrine, huperazine offered a superior result than pyridostigmine against organophosphate toxicity. The combination of carbamic acid and physostigmine produced better results. But these results were associated with distinguished toxic adverse drug reactions including central nervous system deformities ${ }^{[30-32]}$.

There is a natural defense mechanism present in rat and mice, which works against organophosphate poisoning. This mechanism is based on the presence of endogenous scavenger known as carboxylesterase, mainly seen in the plasma of animals. The low dose exposure of organophosphate compounds can be managed with this natural mechanism. The particular enzyme is absent in humans and it is possible to administer exogenous bioscavengers. Still, the effectiveness of these agents is purely based on the concentration of organophosphate compounds exposed. The major disadvantages are immunologic adverse effects after the administration of nonhuman enzymes ${ }^{[30]}$. The effectiveness of the $\mathrm{BChE}$ replacement therapy, blood alkalinisation therapy is unclear and needs effective research ${ }^{[33]}$.

The drugs used to manage Alzheimer's disease including donepezil, huperazine, rivastigmine and galantamine seem to be effective in organophosphate poisoning management. The chemical structures of these agents are shown in below fig. $2^{[34]}$. These drugs, except galantamine exhibit toxic side effects even at therapeutic doses and are found ineffective in post poisoning management. Donapezil, huperazine and rivastigmine exhibit effectiveness only when administered along with anticholinergic agents ${ }^{[35,36]}$. Galantamine is expected to induce more effective results in the management of organophosphate toxicity.

\section{GALANTAMINE}

Galantamine (solid white powder, molecular formula $\mathrm{C}_{17} \mathrm{H}_{21} \mathrm{NO}_{3}$ and molecular weight 287.4) possesses phenanthrene alkaloidal properties and belongs to the class of cholinesterase inhibitors. The drug is capable of producing eight different optical isomers 


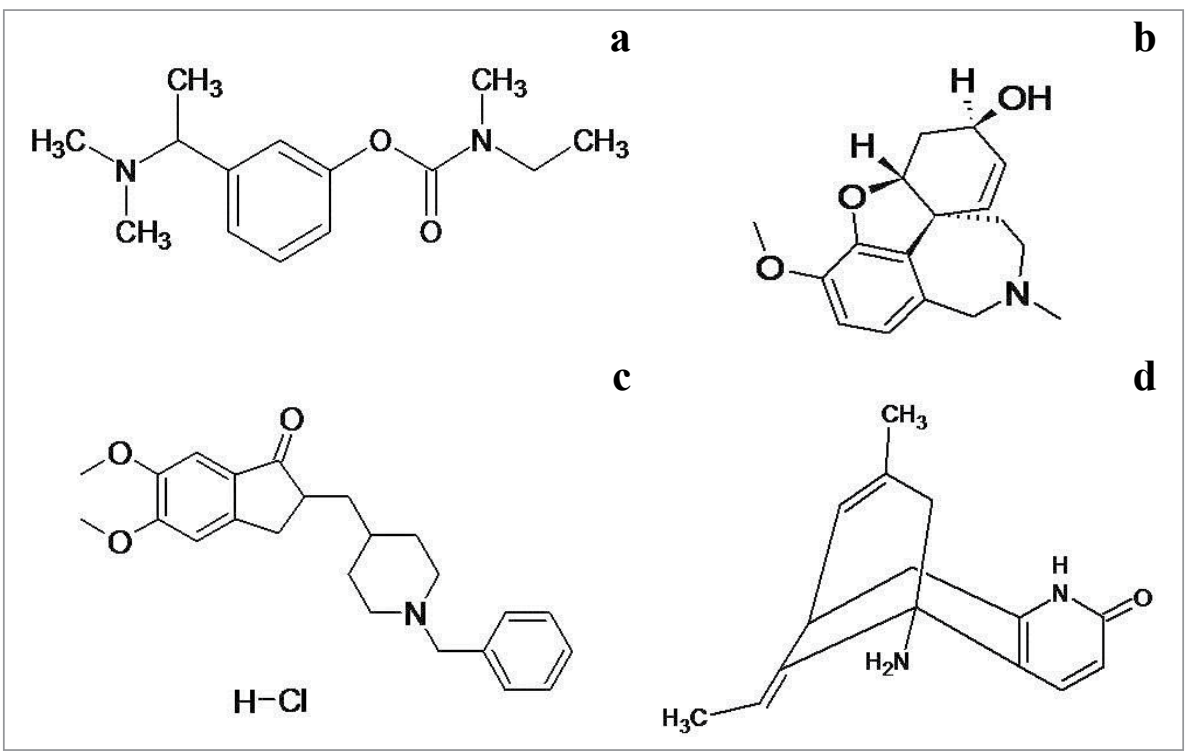

Fig. 2: Chemical structures of drugs.

a. rivastigmine, d. galantamine, c. donapezil and d. huperazine.

as it possesses three chiral centers. This drug was first isolated from Caucasian Snowdrop Galanthus woronowi and Galanthus nivalis and various other sources such as Narcissus, Lycoris and several South African Amaryllidacea species. Synthetically it is a benzazepine derived from norbelladine ${ }^{[37-39]}$.

Pharmacodynamic properties of galantamine were recognized in the early times and were widely prescribed for various psychiatric disorders such as schizophrenia, bipolar disorders, alcohol dependency and depression. These disorders are associated with cholinergic alterations.

As the drug, capable of reversing AChE inhibitors, galantamine was approved by Food Drug Administration (FDA) in May 2011 for treatment of mild to severe Alzheimer's disease ${ }^{[37]}$. In schizophrenia, galantamine was found to be effective in managing the negative symptoms and cognitive dysfunction through the activation of muscarinic receptors. In depression, galantamine regulates the synthesis of brain-derived neurotrophic factor in hippocampal region and causes neurogenesis. This may lead to improvements in behavioral and cognitive impairment. Thus, galantamine is highly related with the management of depression. Similarly, prolonged alcohol intake may cause memory impairment and reduction in ACh levels. Studies reported that higher doses of galantamine can reduces ethanol intake in rats. So galantamine is expected to be beneficial in management of alcohol induced diseases ${ }^{[40]}$. Galantamine is found to be safe and effective in long term treatment of rheumatoid arthritis even in high doses due to its low toxicity and increased elimination characteristics.

\section{Mechanism of action in organophosphate poisoning management:}

The exact mechanism by which galantamine protects from organophosphate toxicity is not well established ${ }^{[38]}$. The distinguished property of galantamine to act as reversible competitive inhibitor of AChE ensures the possibility to use this drug as an effective drug for organophosphate poisoning. The neuroprotectant property of galantamine prevents the neurodegeneration, which is the hall mark of organophosphate toxicity ${ }^{[41,42]}$.

In severe organophosphate toxicity, the increased level of ACh in synaptic cleft for a long duration of time may cause massive desensitization of nicotinic receptors and this may lead to the development of intermediate syndrome. Galantamine can act as allosteric potentiating ligand (APL). APLs ligands are the agents that stimulate the receptors which are different from receptors involved in usual nicotinic agonist and antagonist activities. The activity of an allosteric potentiating ligand was not through neurotransmission process and these activities never proceeded to the development of compensatory mechanism normally follows ${ }^{[43]}$. Thus galantamine causes desensitization of nicotinic receptors (nAChRs) to a substantial extent $^{[42,44]}$.

Organophosphate compounds inhibit cholinesterases 
peripherally and centrally in an irreversible manner. As galantamine can cross blood brain barrier, it reversibly inhibits cholinesterase in blood as well as in brain. The inhibition process becomes gradually insignificant within $6 \mathrm{~h}$ and the peak effectiveness was observed within 30 min after drug exposure ${ }^{[45]}$. However, a significant variation in the extent of AChE inhibition was observed in blood and brain. The blood AChE inhibition was found to be 10 fold greater than brain AChE inhibition. Even though, the decreased rate of reversible brain $\mathrm{AChE}$ inhibition is capable of preventing the irreversible brain AChE inhibition by organophosphate compounds. This process prevents the central nervous system manifestations of organophosphate compounds ${ }^{[11,46]}$.

Galantamine selectively inhibits $\mathrm{AChE}$ and protects BChE in whole blood and erythrocytes. The protected $\mathrm{BChE}$ preserves its scavenger capacity for organophosphate compounds. This property can be considered as an added advantage of galantamine in organophosphate poisoning management compared to physostigmine, pyridostigmine ${ }^{[8,33,47]}$.

\section{Experimental details describing the effectiveness of galantamine $^{[48]}$ :}

The effectiveness of galantamine to manage organophosphate toxicity was experimented. Similar rate and extent of effectiveness was observed against organophosphate as insecticide and warfare agent. All the experiments were conducted in guinea pigs (nonhuman primates). Guinea pigs react specifically when exposed to organophosphate compounds compared to mice and rats. Usually, organophosphate agent exposure induces muscarinic action within 5 to 15 min and central nervous system effects within 15 to $30 \mathrm{~min}$ in animals.

Galantamine (5-6 mg) was administered to guinea pigs intramuscularly $30 \mathrm{~min}$ prior to the exposure of organophosphate compounds. Atropine sulphate (10 $\mathrm{mg} / \mathrm{kg}$ ) was also administered to the animals as a post treatment agent. In this experiment, galantamine was found to be effective with $100 \%$ survival rate with $\mathrm{ED}_{50}$ values of $1.82 \pm 0.37$ or $2.2 \pm 0.50 \mathrm{mg} / \mathrm{kg}$. The optimal dose of galantamine required varies according to the concentration of organophosphate compound exposed to the animal. The group of animals receiving the dose of $16-20 \mathrm{mg} / \mathrm{kg}$ exhibited some mild adverse drug reactions for a short period of time. Thus, galantamine can be considered as an effective prophylactic agent to prevent organophosphate toxicity. This can be applicable to those who are at continuous exposure of organophosphate agents.

Similarly, the effectiveness of galantamine in treating the patients already exposed to organophosphate compounds $\left(\begin{array}{ll}1.5 & \mathrm{LD}_{50}\end{array}\right)$ was also monitored. Immediately after the appearance of organophosphate clinical manifestations, atropine was administered every 3 to $5 \mathrm{~min}$. Each time the doses of atropine given were in 1 to $10 \mathrm{mg}$ range. Galantamine $(8 \mathrm{mg} / \mathrm{kg})$ was found to be effective and provides protection without any lethality. The muscarinic and nicotinic symptoms of organophosphate agents were absent. The duration of effectiveness was related with concentration of organophosphate compound.

The dose of galantamine as a post treatment agent was found to be higher than the dose needed as a pretreatment agent. This can be explained as follows. Organophosphate compounds inhibit AChE enzymes and thus more concentration of galantamine is required in this condition to compete with organophosphate compounds. As the galantamine-induced $\mathrm{AChE}$ inhibition is reversible, the presence of galantamine may protect the patients from lethality. The dose of galantamine varies according to the type of organophosphate compound.

\section{Pharmacokinetics:}

Galantamine has shown increased bioavailability (BA) and decreased protein binding by following linear pharmacokinetics in healthy volunteers. The half-life of the drug was found to be around $7 \mathrm{~h}$. Galantamine is metabolized by CYP3A4 and CYP2D6 enzymes. The metabolites have complete renal elimination by following the metabolic pathways such as glucuronidation, O-demethylation, $\mathrm{N}$-demethylation, $\mathrm{N}$-oxidation, and epimerization ${ }^{[49]}$. The presence of food may cause the delay in absorption but may not alter the bioavailability, volume of distribution $\left(\mathrm{V}_{\mathrm{d}}\right)$, half-life $\left(t_{1 / 2}\right)$ of the drug.

The dose of galantamine to protect organophosphate toxicity is similar to the dose used in Alzheimer's disease management. The peak plasma concentration of galantamine needed to manage organophosphate poisoning $(2.8 \mu \mathrm{M})$ was found to be similar to Alzheimer's disease $(0.2-3 \mu \mathrm{M})$. A plasma concentration of 2-3 $\mu \mathrm{M}$ was recommended to be maintained in patients who are at risk of continuous exposure to organophosphates until the end of exposure ${ }^{[50]}$. Dose of galantamine required after the exposure of 
organophosphate compound was fixed as 3 to $12 \mathrm{mg}$. This can be administered three times a day for a period of one month based on severity of toxicity ${ }^{[48]}$. The dose of galantamine needed for each individual may vary according to the quantity, duration and type of exposed organophosphate compound.

Galantamine is available as the salts of hydrochloride and hydrobromide and formulated in various formulations for oral (liquid solutions, suspensions), transdermal, parenteral (intramuscular, intravenous, intraperitoneal, or subcutaneous administration), rectal, and nasal administration. Immediate release and extended release formulations are also available. Intramuscular and oral formulations were found to be the most preferably suggested formulations among them. For patients who have continuous exposure of organophosphate agents prefers oral administration of galantamine. Atropine is always advised to be used along with galantamine. Presently, the combination of atropine and galantamine (galantamine $12 \mathrm{mg}$ and atropine 1-12 mg) is also available ${ }^{[51]}$. Razadyne ${ }^{\circledR}$, Razadyne $\mathrm{ER}^{\circledR}$, $\operatorname{Reminy}^{\circledR}$, $\operatorname{Nivalin}^{\circledR}$, and Memeron ${ }^{\circledR}$ are the various trade names of galantamine available in the market.

\section{Adverse effects:}

The most common adverse effects associated with galantamine were headache and suppression of appetite. Gastrointestinal side effects like nausea, vomiting, diarrhea, dizziness, abdominal pain were very less frequently reported. Usually galantamine therapy is associated with reduction in the body weight. These concerns can be minimized with slow dose escalations ${ }^{[39,52]}$. The long term exposure of galantamine may induce a risk of abortion in women (less than $0.1 \%$ ) and increases the tendency to develop cardiac hypertension. The overall risk is less in comparison with the organophosphate toxicity.

\section{Use of galantamine in special populations ${ }^{[53,54]}$ :}

The dose reduction of galantamine is recommended to the patients with mild to moderate hepatic impairment and highly restricted in the patients with severe hepatic impairment. Similarly, galantamine administration is strictly restricted in the patients with severe renal impairment whereas patients with mild to moderate renal diseases are advised to take galantamine in altered doses $^{[51]}$. As galantamine excretion is not influenced by the age group of population, geriatric population does not require galantamine dose alteration. Females are reported to have decreased rate of clearance rate compared to men and the effectiveness was not altered based on race. Teratogenicity was reported in animals following the use of galantamine and in humans, no studies were performed to analyze the drug excretion in human breast milk and its safety and efficacy in pregnant women. Presently, the drug is not recommended to pregnant women and lactating mothers. Similarly, the drug is not recommended to pediatric population also.

\section{Drug interactions ${ }^{[3,54]}$ :}

Synergistic result was observed with galantamine when administered with neuromuscular blocker, cholinomimetic and cholinergic agonists. Cimetidine increases the bioavailability of galantamine. Galantamine may not alter the pharmacokinetic and pharmacodynamic properties of warfarin and digoxin. The drugs which are inhibitors of CYP3A4 (ketoconazole. erythromycin) and CYP2D6 (paroxetine) can potentiate the effect of galantamine and the use of these drugs are restricted along with galantamine or adequate dose reduction is recommended. Gastrointestinal adverse effects were associated with galantamine and these symptoms may sustain until the reduction of galantamine drug concentration. Gastroprotective drugs are recommended for use along with galantamine. The uses of drugs with excessive stomach acid release are restricted along with galantamine.

\section{Patient information ${ }^{[53,54]}$ :}

Galantamine is contraindicated in the patients who are allergic towards galantamine hydrobromide and the excipients used. Galantamine can be given twice daily (morning and evening) with or without food. Food does not interfere with the effectiveness of the drug. Patients recommended to use galantamine as a prophylactic agent for long duration, should inform physician if he is taking any other medication as galantamine can interact with many other drugs.

\section{CONCLUSION}

Organophosphate compounds used either in the form of pesticide or as chemical warfare agent can cause sufferings in humans when exposed intentionally or unintentionally. Organophosphate compounds inhibit $\mathrm{AChE}$ and lead to the development of hazardous symptoms. Currently, AChE reactivator and anticholinergic agents are used to manage 
organophosphate toxicity. As these agents have their own drawbacks, research was continued to find most efficacious drug.

The effectiveness of pyridostigmine, physostigmine, tacrine, carboxylesterases and huperazine were monitored and studies were not further preceded due to their long term adverse effects. There are several distinctive properties of galantamine, an established drug for Alzheimer's disease, was focused to check its applicability in organophosphate compound poisoning management. Galantamine showed effectiveness in management of organophosphate toxicity by reversibly inhibiting AChE. As the drug can cross blood brain barrier, it may reversibly inhibit AChE in brain. This property of galantamine may lead to a reduction in severity and extent of central nervous system manifestation. The capacity of galantamine to act as nicotinic allosteric ligand and preserve scavenger capacity of BChE, anticonvulsant properties and ability to prevent neurodegeneration may be found as an added advantage in organophosphate poisoning management.

The effectiveness of galantamine as pretreatment and post-treatment agent was observed in preclinical studies. The drug is associated with good pharmacokinetic properties, less drug interactions and minimal side effects. Easy administration methods were also available. Considering all these facts, it may be concluded that galantamine can be developed as an effective choice in management of organophosphate poisoning and further studies should be performed in humans to confirm these effects in future.

\section{Acknowledgements:}

The authors acknowledge the support provided by the JSS College of Pharmacy, Udhagamandalam, (A constituent college of JSS University, Mysore) for the conduct of this effort. Authors also acknowledge Department of Science and Technology (DST), New Delhi, India for providing Inspire Fellowship to one of the author (Inspire Code- IF130111, Ref: DST/ INSPIRE Fellowship/2013 Dated on 17 May 2013).

\section{Financial support and sponsorship:}

Nil.

\section{Conflicts of interest:}

There are no conflicts of interest.

\section{REFERENCES}

1. Pohanka M, Musilek K, Kuca K. Progress of biosensors based on cholinesterase inhibition. Curr Med Chem 2009;16:1790-8.

2. Pope C, Karanth S, Liu J. Pharmacology and toxicology of cholinesterase inhibitors: uses and misuses of a common mechanism of action. Environ Toxicol Pharmacol 2005;19:433-46.

3. Gupta PK. Pesticide exposure- Indian scene. Toxicology 2004;198:83-90.

4. Eddleston M. Patterns and problems of deliberate selfpoisoning in the developing world. QJM 2000;93:715-31.

5. Sahin HA, Sahin I, Arabaci F. Sociodemographic factors in organophosphate poisonings: a prospective study. Hum Exp Toxicol 2003;22:349-53.

6. Tsai JR, Sheu CC, Cheng MH, Hung JY, Wang CS, Chong IW, et al. Organophosphate poisoning: 10 years of experience in southern Taiwan. Kaohsiung J Med Sci 2007;23:112-9.

7. Singh SP, Aggarwal AD, Oberoi SS, Aggarwal KK, Thind AS, Bhullar DS, et al. Study of poisoning trends in north India-a perspective in relation to world statistics. J Forensic Leg Med 2013;20:14-8.

8. Newmark J. Nerve agents: pathophysiology and treatment of poisoning. Semin Neurol 2004;24:185-96.

9. Sungur M, Guven M. Intensive care management of organophosphate insecticide poisoning. Crit Care 2001;5:211-5.

10. Subash V. Current review on organophosphorous poisoning. Arch Appl Sci Res 2010;2:199-215.

11. Paudyal BP. Organophosphorous poisoning. JNMA J Nepal Med Assoc 2008;47:251-8.

12. Girish T, Kishore GS, Kanav K. Evaluation of incidence, clinical characteristics and management in organophosphorous poisoning patients in a tertiary care hospital. J Toxicol Environ Health 2010;2:73-6.

13. De Bleecker JL, De Reuck JL, Willems JL. Neurological aspects of organophosphate poisoning. Clin Neurol Neurosurg 1992;94:93-103.

14. Eddleston M, Buckley NA, Eyer P, Dawson AH. Management of acute organophosphorous pesticide poisoning. Lancet 2008;371:597-607.

15. Jayawardane $\mathrm{P}$, Dawson AH, Weerasinghe V, Karalliedde L, Buckley NA, Senanayake N. The spectrum of intermediate syndrome following acute organophosphate poisoning: a prospective cohort study from Sri Lanka. PLoS Med 2008;5:147.

16. Senanayake N, de Silva HJ, Karalliedde L. A scale to assess severity in organophosphorous intoxication: POP scale. Hum Exp Toxicol 1993;12:297-9.

17. Basavaraj RPR, Niraj S, Sudhanva VK. Predicting outcome and severity in acute organophosphorous poisoning with clinical scoring and serum cholinesterase levels. J Evol Med Dent Sci 2014;3:13360-69.

18. Persson HE, Sjoberg GK, Haines JA, Pronczuk GJ. Poisoning severity score Grading of acute poisoning. J Toxicol Clin Toxicol 1998;36:205-13.

19. Namba T, Nolte CT, Jackrel J, Grob D. Poisoning due to organophosphate insecticides, Acute and chronic manifestations. Am J Med 1971;50:475-92.

20. Lessenger JE, Reese BE. Rational use of cholinesterase activity testing in pesticide poisoning. J Am Board Fam Pract 
1999;12:307-14.

21. Celik T, Cakir E, Kayir H, Bilgi C, Uzbay IT. The effects of chronic ethanol consumption and withdrawal on passive avoidance task and serum cholinesterase level in rats. Prog Neuropsychopharmacol Biol Psychiatry2005;29:505-9.

22. Ellman GL, Courtney KD, Andres V, Feather-Stone RM. A new and rapid colorimetric determination of acetylcholinesterase activity. Biochem Pharmacol 1961;7:88-95.

23. Thiermann H, Szinicz L, Eyer F, Worek F, Eyer P, Felgenhauer $\mathrm{N}$, et al. Modern strategies in therapy of organophosphate poisoning. Toxicol Lett 1999;107:233-9.

24. Wadia RS. Treatment of organophosphate poisoning. Indian J Crit Care Med 2003;7:85-7.

25. Eyer P, Buckley N. Pralidoxime for organophosphate poisoning. Lancet 2006;368:2110-1.

26. Leikin JB, Thomas RG, Walter FG, Klein R, Meislin HW. A review of nerve agent exposure for the critical care physician. Crit Care Med 2002;30:2346-54.

27. Robenshtok E, Luria S, Tashma Z, Hourvitz A. Adverse reactions to atropine and the treatment of organophosphate intoxification. Isr Med Assoc J 2002;4:535-9.

28. Buckley NA, Karalliedde L, Dawson A, Senanayake N, Eddleston M. Where is the evidence for treatments used in pesticide poisoning? Is clinical toxicology fiddling while the developing world burns? J Toxicol Clin Toxicol 2004;42:113-6.

29. Kassa J, Vachek J. A comparison of the efficacy of pyridostigmine alone and the combination of pyridostigmine with anticholinergic drugs as pharmacological pretreatment of tabun-poisoned rats and mice. Toxicology 2002;177:179-85.

30. Wetherell J, Hall T, Passingham S. Physostigmine and hyoscine improves protection against the lethal and incapacitating effects of nerve agent poisoning in the guineapig. Neurotoxicology 2002;23:341-9.

31. Lallement G, Baille V, Baubichon D, Carpentier P, Collombet $\mathrm{JM}$, Filliat $\mathrm{P}$, et al. Review of the value of huperazine as pretreatment of organophosphate poisoning. Neurotoxicology 2002;23:1-5.

32. Fricke RF, Koplovitz I, Scharf BA, Rockwood GA, Olson CT, Hobson DW, et al. Efficacy of tacrine as a nerve agent pretreatment. Drug Chem Toxicol 1994;17:15-34.

33. Masson P. Evolution of and perspectives on therapeutic approaches to nerve agent poisoning. Toxicol Lett 2011;206:5-13.

34. 'Galantamine, rivastigmine, donepezil, huperazine' structures. Available at http://pubchem.ncbi.nlm.nih.gov.html

35. Van Helden HP, Joosen MJ, Philippens IH. Non-enzymatic pretreatment of nerve agent (soman) poisoning: a brief stateof-the-art review. Toxicol Lett 2011;206:35-40.

36. Nadia AA, Jamal A, Ejaz AK, Rukhsana AS, Rashid D. Acute organophosphate insecticide poisoning. J Coll Physicians Surg Pak 2008;13:71-74.

37. Woodruff-Pak DS, Lander C, Geerts H. Nicotinic cholinergic modulation: galantamine as a prototype. CNS Drug Rev 2002;8:405-26.

38. Barnes CA, Meltzer J, Houston F, Orr G, McGann K, Wenk GL. Chronic treatment of old rats with donepezil or galantamine: effects on memory, hippocampal plasticity and nicotinic receptors. Neuroscience 2000;99:17-23.
39. Gullapalli RP, Aracava Y, Zhuo J, Helal Neto E, Wang J, Makris G, et al. Magnetic resonance imaging reveals that galantamine prevents structural brain damage induced by an acute exposure of guinea pigs to soman. Neurotoxicology 2010;31:67-76.

40. Ago Y, Koda K, Takuma K, Matsuda T. Pharmacological aspects of the acetylcholinesterase inhibitor galantamine. J Pharmacol Sci 2011;116:6-17.

41. Corey-Bloom J. Galantamine: a review of its use in Alzheimer's disease and vascular dementia. Int J Clin Pract 2003;57:219-23.

42. Pereira EF, Hilmas C, Santos MD, Alkondon M, Maelicke A, Albuquerque EX. Unconventional ligands and modulators of nicotinic receptors. J Neurobiol 2002;53:479-500.

43. Diana S, Richard WV, Gary LW. Galantamine: effect on nicotinic receptor binding, acetylcholinesterase inhibition, and learning. Proc Natl Acad Sci USA 2001;98:2089-94.

44. Samochocki M, Hoffle A, Fehrenbacher A, Jostock R, Ludwig J, Christner C, et al. Galantamine is an allosterically potentiating ligand of neuronal nicotinic but not of muscarinic acetylcholine receptors. J Pharmacol Exp Ther 2003;305:1024-36.

45. Jann MW, Shirley KL, Small GW. Clinical pharmacokinetics and pharmacodynamics of cholinesterase inhibitors. Clin Pharmacokinet 2002;41:719-39.

46. Thomsen T, Kaden B, Fischer JP, Bickel U, Barz H, Gusztony $\mathrm{G}$, et al. Inhibition of acetylcholinesterase activity in human brain tissue and erythrocytes by galantamine, physostigmine and tacrine. Eur J Clin Chem Clin Biochem 1991;29:487-92.

47. Thomsen T, Kewitz H. Selective inhibition of human acetylcholinesterase by galantamine in vitro and in vivo. Life Sci 1990;46:1553-8.

48. Albuquerque EX, Pereira EF, Aracava Y, Fawcett WP, Oliveira M, Randall WR, et al. Effective countermeasure against poisoning by organophosphorus insecticides and nerve agents. Proc Natl Acad Sci USA 2006;103:13220-5.

49. Mannens GS, Snel CA, Hendrickx J, Verhaeghe T, Le Jeune $\mathrm{L}$, Bode $\mathrm{W}$, et al. The metabolism and excretion of galantamine in rats, dogs, and humans. Drug Metab Dispos 2002;30:553-63.

50. Mihailova D, Yamboliev I, Zhivkova Z, Tencheva J, Jovovich V. Pharmacokinetics of galantamine hydrobromide after single subcutaneous and oral dosage in humans. Pharmacology 1989;39:50-8.

51. Singh S, Chaudhry D, Behera D, Gupta D, Jindal SK. Aggressive atropinisation and continuous pralidoxime (2PAM) infusion in patients with severe organophosphate poisoning: experience of a northwest Indian hospital. Hum Exp Toxicol 2001;20:15-8.

52. Lilienfed S. Galantamine-a novel cholinergic drug with a unique dual mode of action for the treatment of patients with Alzheimer's disease. CNS Drug Rev 2002;8:159-76.

53. Becker R, Markwell S. Problems arising from the generalizing of treatment efficacy from clinical trials in Alzheimer's disease. Clin Drug Investig 2000;19:33-41.

54. Galasko D. New approaches to diagnose and treat Alzheimer's disease: a glimpse of the future. Clin Geriatr Med 2001;17:393-410. 